\title{
Improved dual-frequency Wilkinson power dividers with Defected Ground Structure
}

\author{
Mahsa Keshavarz Hedayati, Gholamreza Moradi, \\ and Abdolali Abdipour \\ Wave Propagation \& Microwave Research Lab, Electrical Engineering Department, \\ Amirkabir University of Technology \\ 424 Hafez. Ave, Tehran, Iran
}

\begin{abstract}
In this paper, defected ground structures have been implemented in order to obtain effective size reduction and harmonic suppression in dual-frequency Wilkinson power divider (WPD). At first, a dumbbell DGS is applied into dual-frequency WPD and both operating frequencies have been decreased as half as the previous ones. Therefore, $49 \%$ size reduction has been achieved. Second, by using spiral DGS, suppression for the second and third harmonics are achieved. Second harmonic of first operating frequency is suppressed by $-21 \mathrm{~dB}$. Second and third harmonics of second operating frequency are suppressed by $-37 \mathrm{~dB}$. There is a good agreement between simulated and measured results.
\end{abstract}

Keywords: dual-frequency Wilkinson power divider, size reduction, harmonic suppression

Classification: Microwave and millimeter wave devices, circuits, and systems

\section{References}

[1] L. Wu, Z. Sun, H. Yilmaz, and M. Berroth, "A dual-frequency Wilkinson power divider," IEEE Trans. Microw. Theory Tech., vol. 54, no. 1, pp. 278-284, Jan. 2006.

[2] X. Li, Y.-J. Yang, S.-X. Gong, T. Hong, X. Chen, and Y.-J. Zhang, "Design of unequal Wilkinson power divider for dual-band operation with isolation stubs," Electron. Lett., vol. 45, no. 24, pp. 1721-1724, Nov. 2009.

[3] K.-K. M. Cheng and C. Law, "A novel approach to the design and implementation of dual-band power divider," IEEE Trans. Microw. Theory Tech., vol. 56, no. 2, pp. 487-492, Feb. 2008.

[4] J.-S. Kim and M.-B. Kong, "Modified design of Wilkinson power divider for harmonic suppression," Electron. Lett., vol. 45, no. 23, Nov. 2009.

[5] K.-K. M. Cheng and F.-L. Wong, "A new Wilkinson power divider design for dual band application," IEEE Microw. Wireless Compon. Lett., vol. 17, no. 9, pp. 664-666, Sept. 2007.

[6] K.-K. M. Cheng and C. Law, "A novel approach to the design and implementation of dual-band power divider," IEEE Trans. Microw. Theory 
Tech., vol. 56, no. 2, pp. 487-492, Feb. 2008.

[7] S. Srisathit, S. Virunphun, K. Bandudej, M. Chongcheawchmnam, and A. Worapishet, "A dual-band 3-dB three-port power divider based on a two-section transmission line transformer," IEEE Microw. Theory Tech., vol. 1, no. 1, pp. 35-38, Jan. 2003.

[8] D. Draskovic and D. Budimir, "Varactor tuned dual-band Wilkinson power divider," International Symposium on Antennas and Propagation and USNC/URSI National Radio Science Meeting, July 2009.

[9] H. Oraizi and M. S. Esfahlan, "Miniaturization of Wilkinson power dividers by using Defected Ground Structures," Progress In Electromagnetics Research Lett., vol. 4, pp. 113-120, 2008.

[10] D. J. Woo and T. K. Lee, "Suppression of Harmonics in Wilkinson Power Divider Using Dual-Band Rejection by Asymmetric DGS," IEEE Trans. Microw. Theory Tech., vol. 53, no. 6, June 2005.

[11] M. K. Hedayati, G. Moradi, A. Abdipour, and M. Mosalanejad, "A miniaturized dual-frequency Wilkinson power divider using defected ground structure," IEEE APACE 2010 Conf., Malaysia.

\section{Introduction}

Power dividers have an important application in microwave and millimeterwave circuits. In recent years, there is a widespread demand in dual-band power dividers, which are used in multiband mobile phones [1, 2, 3, 4, 5]. Different schematics of dual-frequency Wilkinson power dividers have been discussed in $[2,3,7]$ and $[8]$.

Recently, the Defected Ground Structure (DGS) has found various applications in microwave circuits such as size reduction [9] and harmonic suppression. By implementing of DGS, the effective inductance and consequently the electrical length of the transmission line increase and a noticeable size reduction in microstrip line is achieved [1]. DGS structures also have band rejection characteristic due to their size. Therefore, their resonance frequency can be matched with the second and third harmonics of the circuits corresponding to proper design of DGS parameters.

In this paper, at first we use a dumbbell DGS to reduce the size of the dual-frequency Wilkinson power divider. As can be seen in proposed Wilkinson power divider in [1], two transmission lines with more length compared with that of single-frequency Wilkinson power divider is needed. In order to size reduction which is more necessary in this case, defected ground structure is used. Previously, DGS has been used in single frequency WPD in [10]. In section II, procedure of design and implementation of proper DGS for size reduction is explained. Next, in section III, implementing of DGS in order to suppress second and third harmonics in both operating frequencies is represented.

\section{Implementing of DGS for size reduction}

The two section dual-band WPD introduced by Lei Wu in [1] is employed. 
According to [1], the WPD parameters can be obtained by following equations [1]:

$$
\begin{gathered}
l_{1}=l_{2}=\frac{n \pi}{\beta_{1}+\beta_{2}} \\
Z_{2}=Z_{0} \sqrt{\frac{1}{2 \alpha}+\sqrt{\frac{1}{4 \alpha^{2}}+2}} \\
Z_{3}=\frac{2 Z_{0}^{2}}{Z_{2}} \\
\alpha=\left(\tan \left(\beta_{1} l_{1}\right)\right)^{2} \\
\beta=\frac{2 \pi}{\lambda}
\end{gathered}
$$

In previous equations, $n$ is a positive integer. The WPD operating frequencies are $f_{1}=0.9 \mathrm{GHz}$ and $f_{2}=2.5 \mathrm{GHz}$ [11]. The designed and fabricated dualband WPD is shown in Fig. 1 (a). The simulated and measured $S_{11}, S_{21}$ and $S_{31}$ parameters are shown in Fig. 1 (b). It indicates that at both operating frequencies $f_{1}=0.9 \mathrm{GHz}$ and $f_{2}=2.5 \mathrm{GHz}$, we have an equally coupled and transmitted signal to the output ports. According to measurement, there is an input return loss of $-58 \mathrm{~dB}$ at $0.9 \mathrm{GHz}$ and $-20 \mathrm{~dB}$ at $2.5 \mathrm{GHz}$.

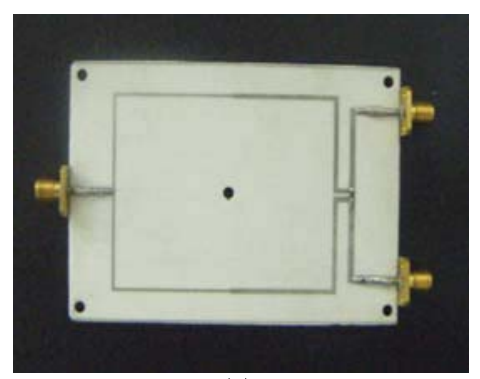

(a)

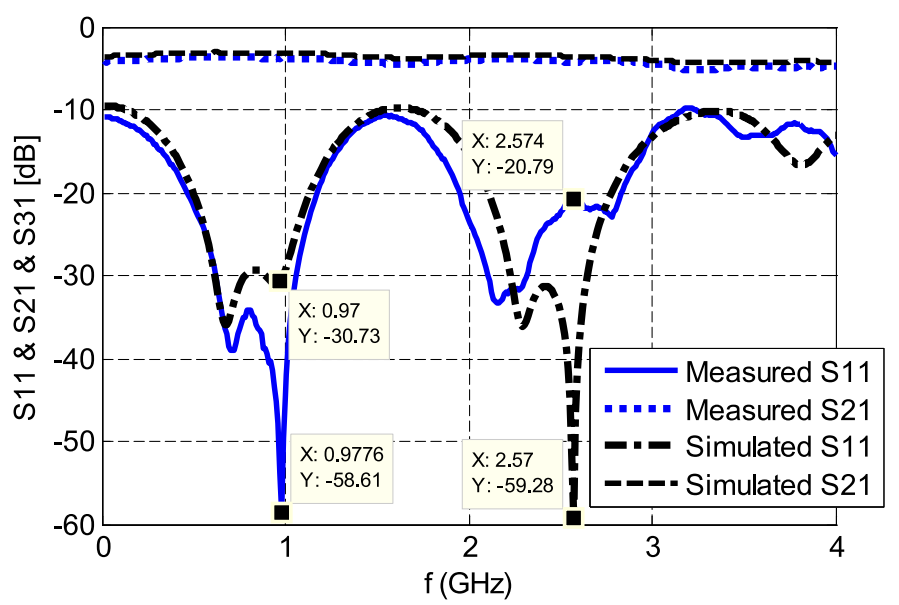

(b)

Fig. 1. (a) Fabricated $3 \mathrm{~dB}$ dual-band WPD. (b) Measured and simulated S-parameters of dual-band WPD [11].

In order to design lower operating frequencies, operating wavelength increases and consequently larger area is needed. But by using DGS, $f_{1}$ is lowered to $0.5 \mathrm{GHz}$ and $f_{2}$ to $1.1 \mathrm{GHz}$ without increasing area. In fact, DGS 
disturbs the current path in the ground plane and so decreases phase velocity. This causes an increase of effective dielectric constant and decrease of the effective wavelength [10]. Therefore, we can decrease the operating frequencies because of decreasing effective wavelength by adjusting characteristic impedance of transmission lines with designing proper dimensions of DGS. In this case, the operating frequencies are lowered to $0.6 f_{1}$ and $0.47 f_{2}$, without using larger quarter wavelength transmission lines, which must be as twice as the previous ones. $\left(l_{1}^{\prime}=l_{2}^{\prime}=\frac{c}{2\left(f_{\left.1^{\prime}+f_{2}{ }^{\prime}\right)}\right.} \approx \frac{c}{f_{1}+f_{2}} \approx 2 l_{1}\right)$.

The substrate RO4003 with thickness of $0.813 \mathrm{~mm}$, a relative permittivity of 3.38 and a conductor thickness of $0.05 \mathrm{~mm}$ is used. We use Ansoft-HFSS to simulate the WPD. The total area is $9.8 \times 6.6 \mathrm{~cm}^{2}$ Fig. 2 (a) shows the proposed dual-band WPD with dumbbell DGS. The dimensions of DGS are $A=0.5 \mathrm{~mm}, B=1.2 \mathrm{~mm}$, and $C=D=4 \mathrm{~mm}$.

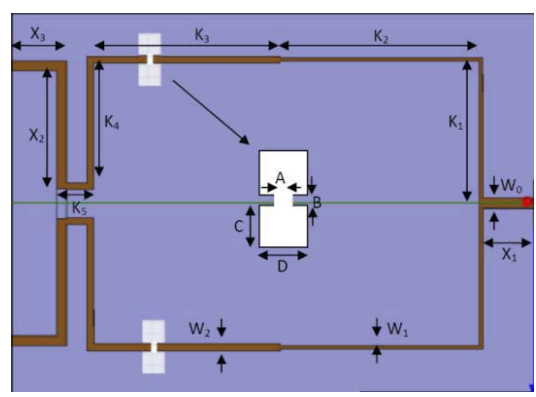

(a)

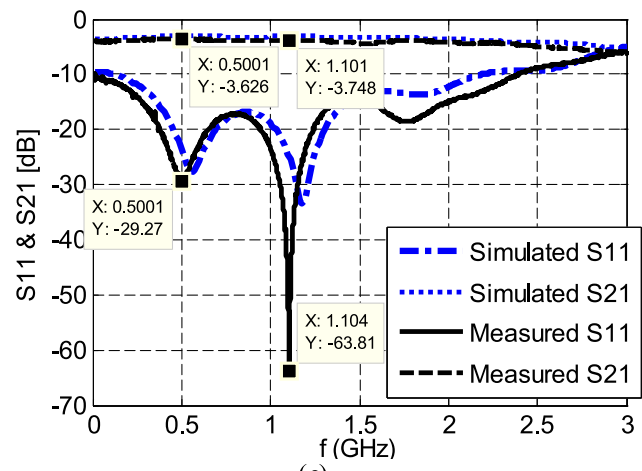

(c)

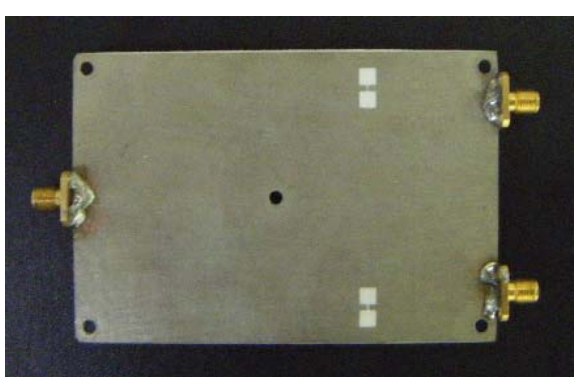

(b)

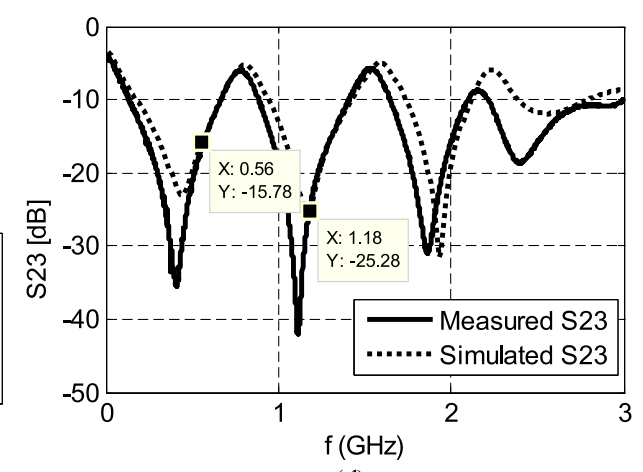

(d)

Fig. 2. (a) A dual-band Wilkinson power divider with dumbbell DGS for $f_{1}=0.5 \mathrm{GHz}$ and $f_{2}=$ $1.1 \mathrm{GHz}$. (b) Bottom view of fabricated 3-dB dual-band Wilkinson power divider with dumbbell DGS. (c) Measured and simulated $S_{21}$ and $S_{11}$ of dual-frequency WPD with DGS. (d) Measured and simulated $S_{22}$ and $S_{23}$ of dual-frequency WPD with DGS.

As mentioned, by implementing of DGS the operating frequencies are decreased without increasing the length of transmission lines. The rectangular area and gap distance of dumbbell DGS and also its location have been optimized in order to reach desired performance at frequencies $f_{1}=0.5 \mathrm{GHz}$ and $f_{2}=1.1 \mathrm{GHz}$. 
Table I contains the values of designed parameters. The values of chip resistor for output ports isolation is $100 \Omega$.

Table I. Values of design parameters [11].

\begin{tabular}{|c|c|c|c|}
\hline \multicolumn{5}{|c|}{ Design parameters values } \\
\hline Parameter & $\begin{array}{c}\text { Designed value } \\
(\mathrm{mm})\end{array}$ & Parameter & $\begin{array}{c}\text { Designed value } \\
(\mathrm{mm})\end{array}$ \\
\hline$W_{0}$ & 1.65 & $K_{3}$ & 31 \\
\hline$W_{1}$ & 0.6 & $K_{4}$ & 24 \\
\hline$W_{3}$ & 1.2 & $K_{5}$ & 5 \\
\hline$X_{1}$ & 8.9 & $A$ & 0.5 \\
\hline$X_{2}$ & 21.1 & $B$ & 1.2 \\
\hline$X_{3}$ & 7.8 & $C$ & 4 \\
\hline$K_{1}$ & 25 & $D$ & 4 \\
\hline$K_{2}$ & 35 & & \\
\hline
\end{tabular}

Fabricated dual-frequency WPDs with dumbbell DGS is shown in Fig. 2(b). In Fig. 2 (c) measured and simulated $S_{11}$ and $S_{21}$ parameters have been shown for WPD with DGS. As shown, measured $S_{11}$ is $-29 \mathrm{~dB}$ at $0.5 \mathrm{GHz}$ and $-63 \mathrm{~dB}$ at $1.1 \mathrm{GHz}$. As can be seen in Fig. 2 (d) measured $S_{23}$ is $-15 \mathrm{~dB}$ at $0.5 \mathrm{GHz}$ and $-25 \mathrm{~dB}$ at $1.1 \mathrm{GHz}$.

\section{Implementing of DGS for harmonic suppression}

In this section, spiral DGS is used in order to suppress second and third harmonics in dual-frequency Wilkinson power divider. Spiral DGS has a sharp rejection band and a deep suppression. Besides, it occupies a smaller area compared with other conventional DGSs. These characteristics make it proper for harmonic suppression in microstrip circuits. Figs. 3 (a) and 3 (b) shows the three spiral DGSs which are designed to resonate at $2 f_{1}, 2 f_{2}$ and $3 f_{2}$. Designed values are: $s=0.4 \mathrm{~mm}, e=0.3 \mathrm{~mm}, p=q=0.35 \mathrm{~mm}$, $a=b=0.25 \mathrm{~mm}, w_{1}=0.6 \mathrm{~mm}$ and $w_{2}=1.2 \mathrm{~mm}$. These structures are applied to the dual-frequency WPD. Fig. 3(c) shows the bottom view of fabricated dual-frequency WPD.

$S_{21}$ and $S_{11}$ of both simulation and measurement are depicted in Fig. 3 (d). As can be seen in Fig. 3 (d) the input return loss at first operating frequency $\left(f_{1}=0.9 \mathrm{GHz}\right)$ is $-19 \mathrm{~dB}$ and at second operating frequency $\left(f_{2}=2.23 \mathrm{GHz}\right)$ is $-21 \mathrm{~dB}$. Suppression for $f_{1 \text { second-harmonic }}=1.8 \mathrm{GHz}$, is $-25 \mathrm{~dB}$ and for $f_{2 \text { second-harmonic }}=4.4 \mathrm{GHz}$ and $f_{2 \text { third-harmonic }}=6.6 \mathrm{GHz}$ is $-37 \mathrm{~dB}$.

\section{Conclusion}

In this paper defected ground structure has been implemented with Dualband Wilkinson power divider for the first time to reduce its size and suppress second and third harmonics of operating frequencies, which previously has been done for single-frequency WPD. Therefore, by implementing dumbbell DGS, $49 \%$ size reduction is obtained due to decrease the both operating 


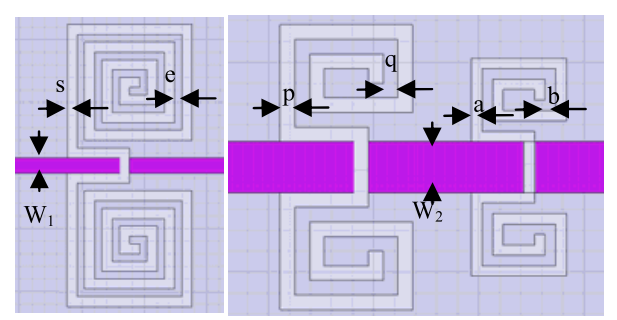

(a)

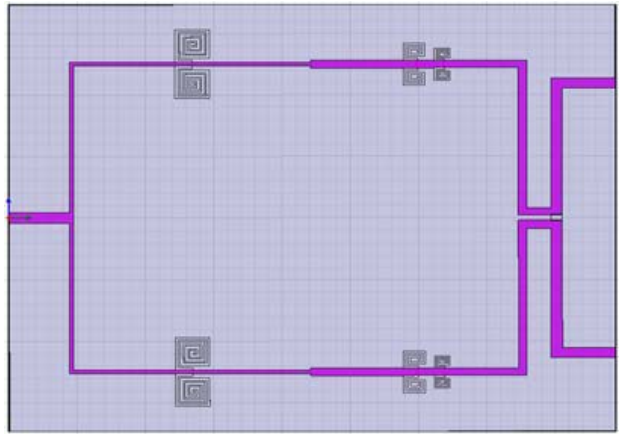

(b)

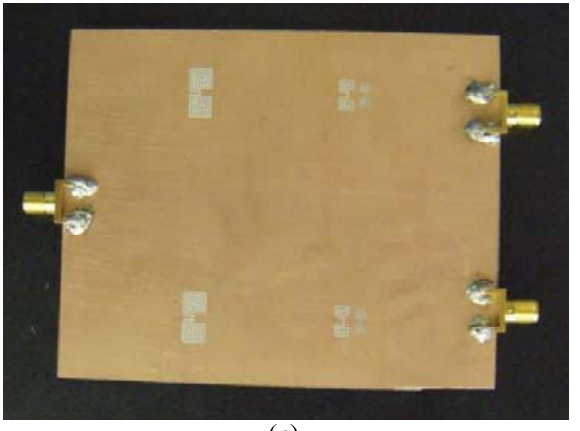

(c)

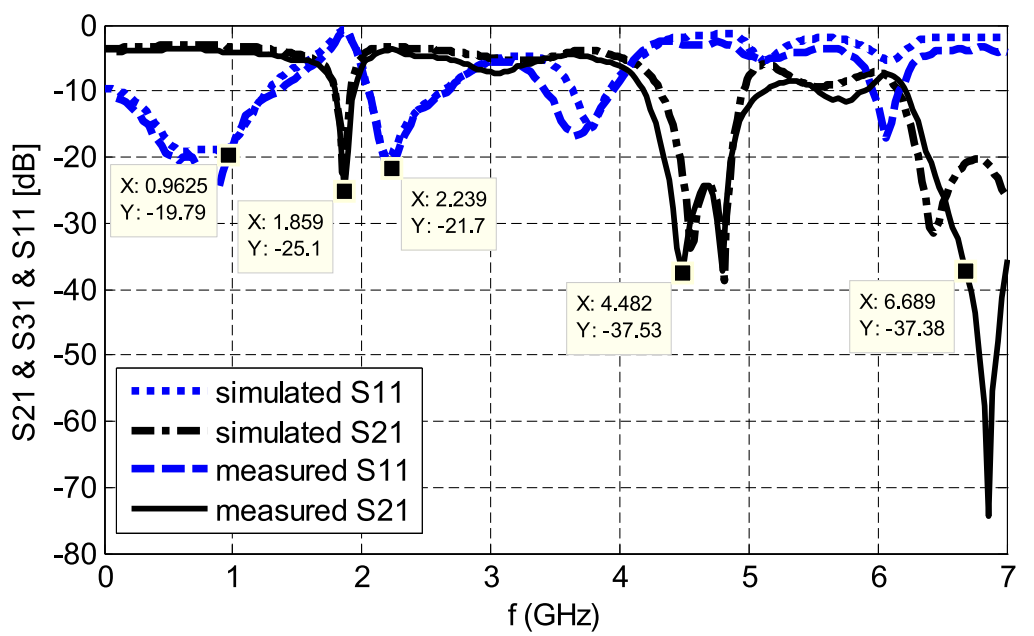

(d)

Fig. 3. (a) dimensions of spiral DGSs. (b) A dual-band Wilkinson power divider with spiral DGS for $f_{1}=$ $0.9 \mathrm{GHz}$ and $f_{2}=2.5 \mathrm{GHz}$. (c) Bottom view of fabricated 3-dB dual-band Wilkinson power divider with spiral DGS. (d) Measured and simulated S-parameters of dual-frequency WPD with DGS.

frequencies as half as the WPD without DGS. Also by using spiral DGSs, the second and third harmonics are properly suppressed. This method can be used in other microstrip circuits.

\section{Acknowledgments}

The authors would like to thank Mr. Mosalanejad and Mr. Mirzavand of mm-wave Research Lab. For their help in measurement. 